\begin{tabular}{|l|l|l||}
\hline \multicolumn{2}{|c|}{ PublisherInfo } \\
\hline \hline PublisherName & $:$ & BioMed Central \\
\hline \hline PublisherLocation & $:$ & London \\
\hline \hline PublisherImprintName & $:$ & BioMed Central \\
\hline \hline
\end{tabular}

\title{
The Canadian C-Spine Rule for Radiography in alert and Stable Trauma Patients
}

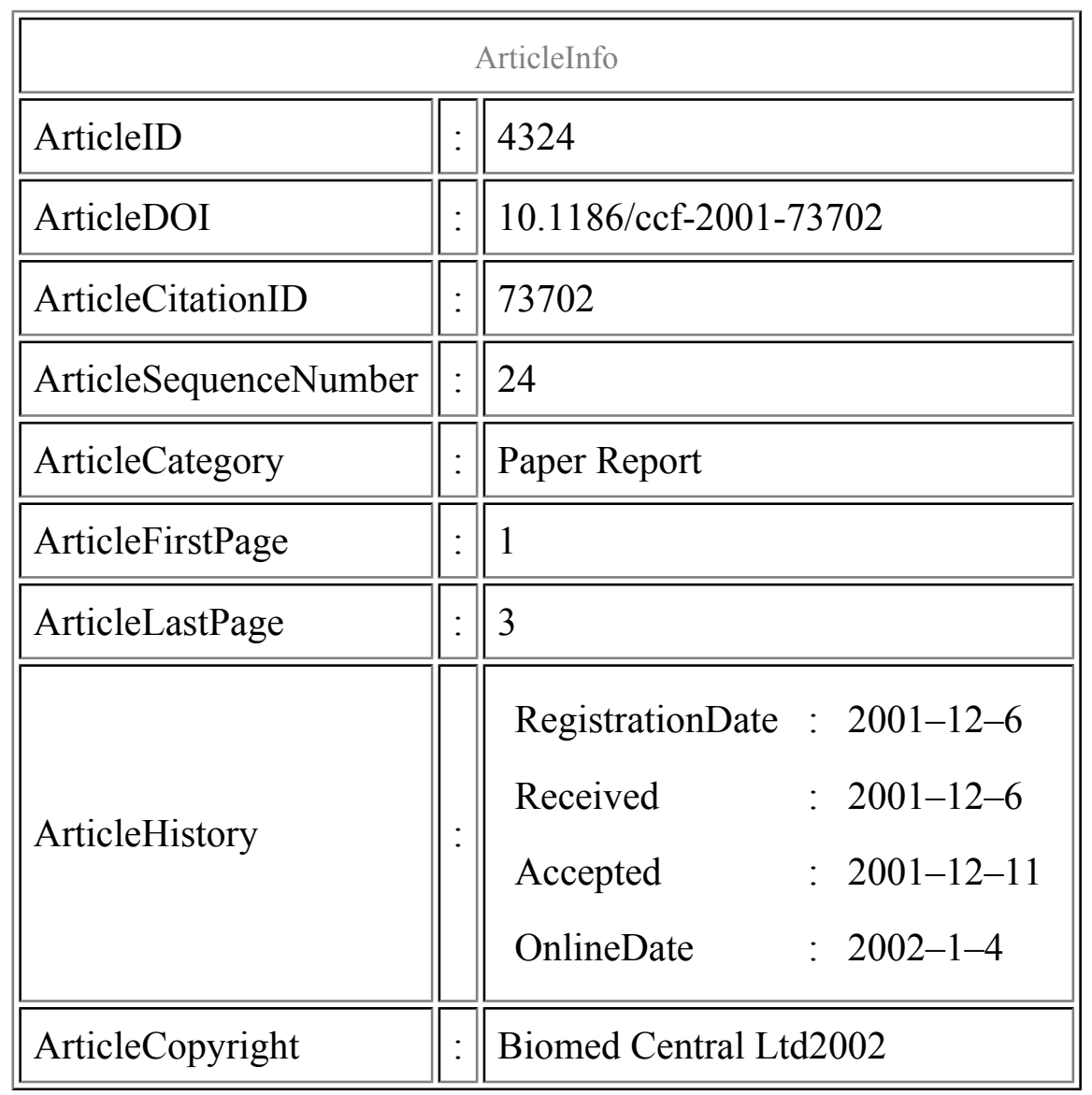




\begin{tabular}{|l||l|l||}
\hline ArticleGrants & $:$ & \\
\hline \hline ArticleContext & $:$ & 1305466 \\
\hline
\end{tabular}

Arpan Guha, ${ }^{\text {Affl }}$

Aff1 University of Aintree, Liverpool, UK

\section{Keywords}

injury, cervical spine; radiological imaging; alert, stable trauma patients

\section{Context}

The cervical spine (C-spine) of trauma victims has been routinely imaged radiologically to rule out bony injury. Many trauma experts find this exercise unnecessary in the majority of cases who are alert, and without clinical suspicion of injury. This study has three aims: to evaluate the possibility of being more selective and specific in ordering $\mathrm{C}$-spine $\mathrm{X}$-rays in trauma patients who are alert and stable; to examine possible predictor variables against actual patient outcome; and to provide a 'rule' that will be clinically effective in decision-making.

\section{Significant findings}

A variety of data were collected from patients with blunt trauma. These variables (e.g. mechanism of injury, neck pain, whether radiography was performed, etc) were then analyzed to find the best combination of predictor variables for detecting clinically important $\mathrm{C}$-spine injury with high sensitivity and specificity. This information was used to derive a rule, which was validated by comparing the classification of patients to their actual status.

Radiology identified clinically significant C-spine injury in $151(1.7 \%)$ patients. The derived rule identified these with a sensitivity of $100 \%$ (95\% confidence interval) and a specificity of $42.5 \%(95 \%$ $\mathrm{CI})$. The authors were able to provide recommendations for situations where $\mathrm{C}$-spine radiography is warranted so that resources are used efficiently without jeopardising patient care. Finally, they derived the present 'Canadian C-spine rule'. 


\section{Comments}

At present there is no well defined algorithm based on research that would allow clinicians to minimise radiological imaging of the C-spine without putting patients at risk. This study attempts to fill that gap in our practice.

There is a potential to miss clinically unimportant (i.e. spinal injury that requires neither stabilization, nor follow up). There were also some patients in the study who did not undergo C-spine radiography if the attending doctors felt that it was not warranted (which is normal practice in Canada).

\section{Methods}

A total of 8924 adult patients with significant acute blunt trauma to the head or neck presented to the Emergency Departments of 10 large Canadian community and University hospitals, these were studied as a prospective cohort. Patients were alert and stable as defined by cardiorespiratory parameters.

The primary outcome measure was the incidence of clinically important C-spine injury. Patients underwent plain radiography of the $\mathrm{C}$-spine and some also had flexion-extension views and CT of the Cspine. Patients who did not have any diagnostic radiological imaging were followed up for 14 days.

\section{Additional information}

\section{References}

1. Stiell IG, Wells GA, Vandemheen KL, Clement CM, Lesiuk H, De Maio VJ, Laupacis A, Schull M, McKnight RD, Verbeek R, Brison R, Cass D, Dreyer J, Eisenhauer MA, Greenberg GH, MacPhail I, Morrison L, Reardon M, Worthington J: The Canadian C-Spine Rule for Radiography in alert and Stable Trauma Patients. JAMA. 2001, 286: 1841-1848. 